\title{
EL POR QUE DE UNA EDICION. RECREACION POLITICA \\ DE NICOLAS DE ARRIQUIBAR. \\ DEL USO DE LA ARITMETICA POLITICA \\ DE CHARLES DAVENANT ${ }^{1}$
}

\author{
JOSE MANUEL BARRENECHEA \\ Universidad de Deusto
}

Esta obra, fruto del trabajo conjunto de investigación de Jesús Astigarraga y José Manuel Barrenechea ${ }^{2}$, ha contado con la ayuda del Instituto Vasco de Estadística que celebra su nacimiento patrocinando esta reedición a través de un convenio con la Universidad de Deusto.

Un poco de bistoria. Marco de referencia de la obra

Un repaso a nuestra historia reciente podría centrar el marco de referencia en el que se encuadra el libro. En el año 1779 publicaba la Real Sociedad Bascongada de los Amigos del País una obra que recogía dos aportaciones fundamentales al pensamiento económico internacional y local. Por un lado, la primera traducción castellana de Of the Use of Political Aritbmetick de Charles Davenant, que supone un paso decisivo en la difusión de la aplicación de los métodos cuantitativos a los problemas económicos. De otra parte, la Recreación Politica, de Nicolás de Arriquíbar, obra en la que el comercianteeconomista bilbaíno, haciendo uso de dichos instrumentos, da consistencia teórica al conjunto de ideas reformadoras de la primera Sociedad ilustrada nacida en España: la Bascongada de los Amigos del País.

'Edición prologada y anotada por Jesús Astigarraga y José Manuel Barrenechea, Bilbao, 1987, 294 pp. (distribución: Ediciones Mensajero, S. A.).

- Jesús Astigarraga (San Sebastián, 1959) es Licenciado en Ciencias Económicas y autor de una tesis doctoral sobre el pensamiento económico de la Real Sociedad Bascongada de los Amigos del País, que clarificará el papel desempeñado por esta institución ilustrada, mostrándola desde perspectivas hasta ahora inéditas. José Manuel Barrenéchea (Bilbao, 1949) es Doctor en Ciencias Económicas y profesor de Economía e Historia del Pensamiento Económico en la Universidad de Deusto; es autor de Valentín de Foronda, reformador y conomista ilustrado (Vitoria, 1984), obra en la que se estudia el pensamicnto de otro economista vasco, de enorme trascendencia en la difusión de las ideas liberales en la última parte del siglo xviı. Ambos autores son especialistas en historia del pensamien. to económico y, muy en particular, en la de las ideas económicas elaboradas en el País Vasco, a cuyo conocimiento han colaborado con diversos trabajos y artículos. 
Si Charles Davenant es considerado hoy en día como uno de los padres de la estadística económica, a Nicolás de Arriquíbar le debemos reconocer como pionero en la búsqueda y análisis de datos que pudieran servir de materiales seguros para aquellos a cuyo cargo estaba la política económica de la nación, así como un importante predecesor de cuantos se han esforzado por lograr, de forma numérica, una fotografía, lo más exacta posible, de la realidad económica. No debe extrañar que la Real Sociedad Bascongada de los Amigos del País decidiera, a la muerte de Arriquíbar, publicar la Recreación Política, precedida de la traducción de la obra de Davenant. El autor había participado muy activamente en la vida interna de la Sociedad $\mathrm{y}$ en cuantos proyectos industriales y comerciales se promovían desde su dirección; hasta el punto de que el modelo de desarrollo propuesto en la Recreación Política informa e inspira cuantas iniciativas económicas surgen de su seno. Con el tiempo, se convertiría en el libro de texto de los estudiantes del Seminario de Bergara y de varias generaciones ilustradas.

\section{El «por qué» de la reedición}

Esta reedición no sólo cumple el objetivo de hacer justicia a un personaje tan significativo en la historia del pensamiento económico de Euskadi, sino que pone en manos del especialista en historia o en economía del siglo xviıI unos textos de obligada consulta, y en las del simple interesado en nuestro pasado, un libro ameno que hasta ahora era de difícil consulta en nuestras bibliotecas.

Los autores, a cuyo cargo ha corrido la preparación de la obra, han sido escrupulosos en el respeto al original y, aunque han modernizado la ortografía y hecho más inteligible el texto, lo han mantenido fiel al de la edición de 1779.

Las 145 notas, a pie de página, que lo acompañan, constituyen un estudio preciso y detallado de las fuentes del pensamiento económico de Arriquíbar, e iluminan su modelo de desarrollo con las ideas económicas dominantes en la Europa de finales del siglo xvin. Con su lectura se hace posible interpretar la Recreación Política como una respuesta crítica a las ideas de la primera escuela de economía surgida en Occidente -la fisiocracia de Quesnay en la versión del Marqués de Mirabeau- y como un intento de impedir que las políticas de la monarquía borbónica se vieran influidas por la corriente entonces en boga en Francia.

En el Estudio Preliminar se abordan, por fin, en un amplio capítulo que precede a la reedición, una serie de aspectos biográficos y bibliográficos acerca 
de Arriquíbar y su incidencia en la literatura moderna. En él se estudian detenidamente las preconcepciones sobre la vida económica de Nicolás de Arriquibar, su modelo de desarrollo y el parentesco con otros sistemas coetáneos, el programa de reformas propuesto y la modernidad de los aparatos analíticos utilizados por el autor. 